\title{
Combined interscalene and supraclavicular brachial plexus block using ultrasound guidance versus general anaesthesia for brachioaxillary graft in patients with chronic renal failure
}

\author{
Heba A Saad', Mona A Hashish ${ }^{2}$, Doaa G Diab ${ }^{3}$, Nevert A Abdel Ghaffar ${ }^{4 *}$ \\ Resident $^{1}$, Professor ${ }^{2}$, Assistant Professor ${ }^{3}$, Lecturer ${ }^{4 *}$, Anaesthesia, Intensive care and Pain \\ management, Faculty of Medicine, Mansoura University, 35516, Egypt.
}

Background: Anaesthesia for patients with chronic renal failure (CRF) is a challenge. We compared combined interscalene (ISB) and supraclavicular (SCB)block using ultrasound guidance versus general anesthesia in patients with CRF undergoing brachioaxillay graft surgery.

Methods: This randomized open label blind end-point pilot study was conducted in Mansoura University- Hospital, Egypt from January 2018 to July 2019. We enrolled 60 patients with CR Funder going brachioaxillary graft surgery. GA group $(n=30)$ received general anaesthesia while RA group $(n=30)$ received combined ISB and SCB. We evaluated numerical rating scale (NRS), surgeon and patient satisfaction, onset and duration of motor and sensory block, duration of surgery and complications.

Results: NRS statistically decreased in RA group. The first need of analgesia significantly delayed, and the frequencies of analgesia requirement were less in RA group. Surgeon and patient satisfaction were similar in both groups. The onset of sensory block was 4.37 minutes and lasted for 9.5 hours while the onset of motor block was 6.73 minutes and lasted for 6 hours. No complications were detected in both groups.

Conclusion: Combined ISB and SCB technique is an excellent alternative to general anaesthesia in patients with CRF undergoing brachioaxillary graft. It implies better surgeon and patient satisfaction with lower NRS and frequency of analgesia requirement with delayed first need of analgesia.

Keywords: Interscalene; supraclavicular; brachioaxillary; renal failure

\section{Introduction}

Anaesthesia for patients with chronic renal failure $(\mathrm{CRF})$ is a challenge without consensus on the ideal anaesthetic technique. Brachial plexus block (BPB)using ultrasound guidance is routinely used for upper limb anaesthesia and analgesia. ${ }^{1} \mathrm{BPB}$ has many approaches depending upon the area to be anaesthetized in the upper limb. The interscalene block (ISB) covers the lateral two thirds of the clavicle, proximal humerus and the shoulder. ${ }^{2}$

*Correspondence: Nevert A. Abdel Ghaffar

E mail: nevertadel@mans.edu.eg

https://orcid.org/0000-0002-0345-0870

Received: $18 / 09 / 2019$

Accepted: $18 / 03 / 2020$

DOI: http:/doi.org/10.4038/slja.v28i2.8501

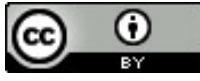

So it is not recommended in distal upper limb surgery due to lack of the inferior trunkblockade. ${ }^{3}$ While the supraclavicular block (SCB) is used for distal third of humerus, elbow, forearm, wrist and hand surgeries with limited usage for shoulder and proximal humeral surgeries. ${ }^{4,5}$ Therefore, the combined interscalene and supraclavicular approaches of BPB could compensate the shortage of each approach alone for whole upper limb anaesthesia needed in brachioaxillary graft surgery.

Arteriovenous access has been accepted as the cornerstone of survival for patients with CRF on dialysis. Arteriovenous grafts are alternative to vascular access when all other venous options as indwelling catheters and arteriovenous fistulae have been exhausted. Although they require a longer surgical time, expertise and material costs, their complications and infection are lower than other vascular access. ${ }^{6}$ 
In this study, we compared the combined ISB and SCB using ultrasound guidance versus general anaesthesia in patients with CRF undergoing brachioaxillay graft surgery.

\section{Material and methods}

Study design and participants

Our randomized open label blind end-point pilot study was conducted in Mansoura University Hospital, Egypt from June 2018 to July 2019. The study was approved by Institutional Research Board and registered in ClinicalTrial.gov. We enrolled 60 patients with CRF aged from 20 to 60 years of both genders undergoing brachioaxillary graft.

We excluded those with a history of allergy to local anaesthetics, having neuromuscular, neurological, psychiatric disorders, uncompensated hepatic, cardiac or respiratory disease, infection at the block injection site, coagulation disorders and body mass index $(\mathrm{BMI})>30$.

\section{Sample size}

It was calculated using $\mathrm{G}^{*}$ Power 3.0.10 based on a pilot study using t-test for comparison using NRS as primary outcome. We needed minimally 28 cases in each group to detect $15 \%$ difference with $80 \%$ power and alpha error of 0.05 . We increased the sample to 30 cases to overcome dropouts.

\section{Randomization}

Patients were randomly allocated using fixed size blocks (block size of 3). GA group $(n=30)$ received general anaesthesia while $\mathrm{RA}$ group $(n=30)$ received combined ISC and SCB $(20 \mathrm{ml}$ isobaric bupivacaine $0.5 \%+10 \mathrm{ml}$ lidocaine $2 \%$, total volume $30 \mathrm{ml}$ divided into $20 \mathrm{ml}$ for SCB and $10 \mathrm{ml}$ for ISB).

All patients were subjected to a dialysis session one day before surgery. Basal laboratory investigations as complete blood count, coagulation profile (activated partial thromboplastin time, prothrombin time and international normalized ratio); arterial blood gases, electrocardiogram and echocardiogram (if needed) were done after dialysis. Written informed consent was obtained from patients.
Numerical rating scale (NRS) was explained to all patients $(0=$ no pain and $10=$ worst pain $){ }^{7}$ Patients were sedated using fentanyl $0.5 \mu \mathrm{g} / \mathrm{kg}$ intravenous to maintain verbal contact.

GA group

After pre-oxygenation, general anaesthesia was induced using $2 \mathrm{mg} / \mathrm{kg}$ propofol and $1 \mu \mathrm{g} / \mathrm{kg}$ of fentanyl. After loss of consciousness, $0.5 \mathrm{mg} / \mathrm{kg}$ of atracurium was injected. The endotracheal tube (ETT) was placed and inflated. The patient was mechanically ventilated to adjust end tidal $\mathrm{CO}_{2}(35$ $-40 \mathrm{mmHg}$ ) and anaesthesia was maintained using $1.2 \%$ isoflurane in $3 \mathrm{~L}$ of $50 \%$ oxygen mixed with air. Increments of fentanyl $(0.5 \mu \mathrm{g} / \mathrm{kg})$ and atracurium $10 \mathrm{mg}$ were used and the haemodynamic values were maintained within $20 \%$ of the basal values. At the end of surgery, the residual muscle relaxant was reversed with $0.02 \mathrm{mg} / \mathrm{kg}$ atropine and $0.05 \mathrm{mg} / \mathrm{kg}$ neostigmine.

\section{$R A$ group}

We placed the patient in supine position with the head turned to the contralateral side $\left(45^{\circ}\right)$. Ultrasound (Phillips, clearvue 350, USA) with a high frequency linear probe(4-12MHZ) was used. Blocks were done by a single member of the anaesthesia team experienced in ultrasonography. We performed SCB first to make sure that the patient can feel any pain or pressure during the injection of both blocks.

\section{Supraclavicular block}

At the supraclavicular fossa, a $22 \mathrm{G}$ needle $75 \mathrm{~mm}$ was advanced in a plane from lateral to medial to the corner pocket between the subclavian artery medially, the first rib inferiorly and the plexus superiorly, where the lower trunk commonly lies (Figure 1a).Then we injected $10 \mathrm{ml}$ of the local anaesthetic mixture while the other $10 \mathrm{ml}$ was injected just lateral and above to the subclavian artery. ${ }^{8}$

Interscalene block

The linear probe was placed at the cricoid cartilage level (Figure 1b).A 22G needle $75 \mathrm{~mm}$ was inserted in a plane approach from lateral to medial toward the inter-scalene groove between the anterior and middle scalene muscles. The anaesthetic mixture $10 \mathrm{ml}$ was injected toward $\mathrm{C} 5$ and $\mathrm{C} 6$ nerve roots to block nerves out of SCB. ${ }^{9}$ 


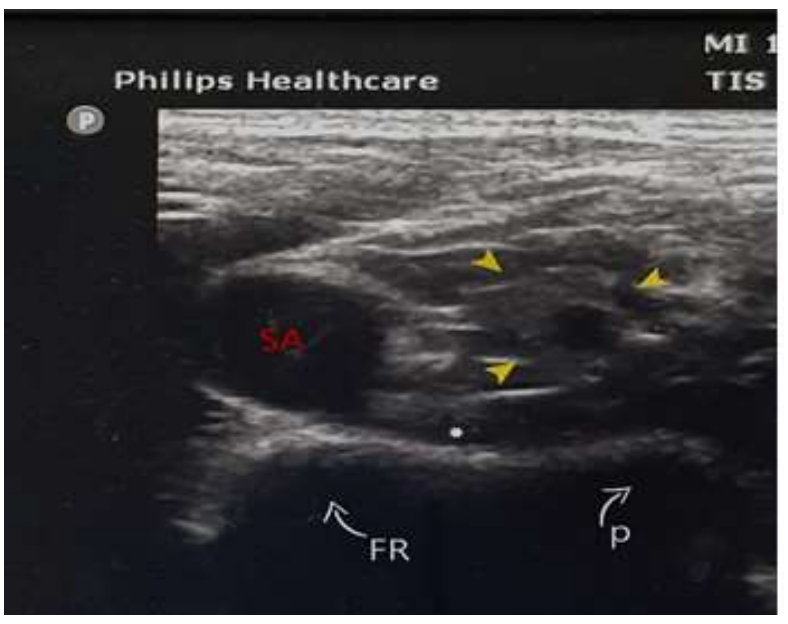

Figure 1a: Supraclavicular brachial plexus (yellow arrows), corner pocket*, $F R$ first rib, $S A$ subclavian artery, $P$ pleura.

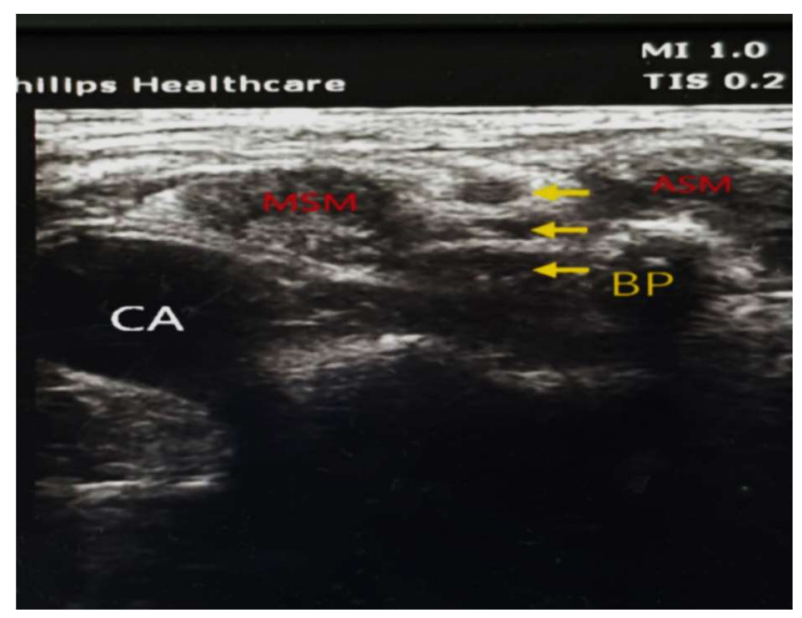

Figure 1b: Interscalene brachial plexus (yellow arrows), $C A$ carotid artery, $M S M$ middle scalene muscle, $A S M$ anterior scalene muscle.

The sensory block was assessed and graded on a three-point scale $(0=$ loss of light touch sensation; $1=$ loss of pin prick sensation; $2=$ normal sensation). ${ }^{10}$ We estimated the time of sensory block onset starting from the end of injection to total loss of pinprick sensation.

Motor block was complete when loss of movement was observed in all tested areas (four major nerves: ulnar by fifth finger flexion, median by third finger flexion, radial by thumb abduction and musculo-cutaneous by elbow flexion). Grading for motor block was measured using the following scale: $2=$ normal motor power, $1=$ partial weakness and $0=$ complete paralysis. ${ }^{11} \mathrm{We}$ estimated the time of motor block onset starting from the end of injection to complete paralysis.

Motor and sensory blocks were assessed every 5 minutes until 30 minutes after injection. Grades 1 and 2 in both blocks were considered failure of block and were excluded from the study.

NRS was recorded for 24 hours after surgery, $1 \mu \mathrm{g} / \mathrm{kg}$ fentanyl intravenous was given if NRS $\geq 4$; surgeon and patient satisfaction was measured by satisfaction visual analogue score $(0=$ not satisfied and $100=$ entirely satisfied $)^{12}$. Duration of surgery was estimated as GA group started from the time of induction and RA group started from the performance of supraclavicular block.

Primary outcomes were NRS and surgeon and patient satisfaction. Secondary outcomes were the time of block onset and durations in RA group, the first need of analgesia and number of times analgesia was required in the 24 hours postoperatively, surgery duration and rate of complications.

\section{Statistical analysis}

We used SPSS version 22. We used independent sample T-test and Mann-Whitney $U$ test for analysis of parametric and non-parametric data, respectively. Chi-square test was used for comparing categorical data.

\section{Results}

There were no statistically significant differences regarding age, gender or BMI in both groups. The first need of analgesia was significantly delayed in RA group. Also, the frequencies of analgesia requirement were lower in RA group $(\mathrm{P}<0.001$, Table 1). 


\begin{tabular}{|l|l|l|l|}
\hline & $\begin{array}{l}\text { GA group } \\
(\mathrm{n}=30)\end{array}$ & $\begin{array}{l}\text { RA group } \\
(\mathrm{n}=30)\end{array}$ & $\mathrm{P}$ \\
\hline Age(years) & $47.67 \pm 14.8$ & $48.33 \pm 15.3$ & 0.86 \\
\hline $\begin{array}{l}\text { Gender*: Female } \\
\text { Male }\end{array}$ & $\begin{array}{l}12(40) \\
18(60)\end{array}$ & $\begin{array}{l}14(46.7) \\
16(53.3)\end{array}$ & 0.6 \\
\hline BMI $\left(\mathrm{Kg} / \mathrm{m}^{2}\right)$ & $23.33 \pm 2.5$ & $23.73 \pm 3.2$ & 0.59 \\
\hline $\begin{array}{l}\text { First need of } \\
\text { analgesia(hours) }\end{array}$ & $0.33 \pm 0.2$ & $8.9 \pm 2.3$ & $<0.001$ \\
\hline $\begin{array}{l}\text { Frequencies of } \\
\text { analgesia requirement }\end{array}$ & $4.03 \pm 0.72$ & $1.6 \pm 0.8$ & $<0.001$ \\
\hline $\begin{array}{l}\text { Duration of surgery } \\
\text { (minutes) }\end{array}$ & $100.83 \pm 17.3$ & $104.67 \pm 14.02$ & 0.35 \\
\hline
\end{tabular}

Table 1: Clinical characteristics, surgery duration and analgesia needs.

All data are shown as mean (SD) except ${ }^{*}$ number (percent), BMI = body mass index.

Surgeon and patient satisfaction were similar in both groups ( $\mathrm{P}>0.05$, Table 2$)$.

Table 2: Surgeon and patient satisfaction

\begin{tabular}{|l|l|l|l|}
\hline Satisfaction characteristics & $\begin{array}{l}\text { GA group } \\
(\mathrm{n}=30)\end{array}$ & $\begin{array}{l}\text { RA group } \\
(\mathrm{n}=30)\end{array}$ & $\mathrm{P}$ \\
\hline Surgeon satisfaction & $90 \pm 30.5$ & $89.5 \pm 12.1$ & 0.93 \\
\hline Patient satisfaction & $83.17 \pm 17.7$ & $90.2 \pm 15.5$ & 0.11 \\
\hline
\end{tabular}

Data are shown as mean (SD).

The meantime of sensory block onset was $4.37 \pm 0.96$ minutes and lasted for 9.5(4-24) hours, while the mean time of motor block onset was $6.73 \pm 1.36$ minutes and lasted for 6(4-18) hours.

NRS statistically decreased in RA group than GA group during the 24-hour postoperative period (Table 3).

Table 3: Numerical rating scale (NRS) among studied groups

\begin{tabular}{|l|l|l|l|}
\hline Time & GA group $(\mathrm{n}=30)$ & RA group $(\mathrm{n}=30)$ & $\mathrm{P}$ \\
\hline $1 \mathrm{~h}$ & $6(4-7)$ & 0 & 0.001 \\
\hline $2 \mathrm{~h}$ & $5(4-7)$ & 0 & 0.001 \\
\hline $4 \mathrm{~h}$ & $5(4-6)$ & $0(0-7)$ & 0.001 \\
\hline $6 \mathrm{~h}$ & $4(3-6)$ & $0(0-7)$ & 0.001 \\
\hline $8 \mathrm{~h}$ & $4(3-5)$ & $1(0-5)$ & 0.001 \\
\hline $12 \mathrm{~h}$ & $3(3-4)$ & $2(0-3)$ & 0.001 \\
\hline $18 \mathrm{~h}$ & $2.5(2-3)$ & $1.5(0-3)$ & 0.001 \\
\hline $24 \mathrm{~h}$ & $2(1-3)$ & $1(0-2)$ & 0.001 \\
\hline
\end{tabular}

Data are shown as median (range).

Three patients in RA group had Horner's syndrome. No other complications were observed in both groups.

\section{Discussion}

Vascular access surgery either fistula or graft is the preferred technique for patients with CRF on haemodialysis. Anaesthesia for those patients is a challenge and needs further skills. ${ }^{13}$

General anaesthesia may decrease renal blood flow up to $50 \%$ leading to reduced nephrotoxic drugs excretion. ${ }^{14}$ Despite BPB providing a promising alternative to other anaesthetic techniques due to less exposure to the various anaesthetic drugs, vasodilator effect, early mobility and excellent postoperative analgesia ${ }^{15}$, there is no evidence for the best approaches of BPB for brachioaxillary graft surgery.

Because missing of C5-C6 nerve roots with SCB, there is a limitation of its usage in shoulder and proximal upper extremities surgeries. ${ }^{4,5}$ So, we studied the efficacy of combined SCB and ISB as a sole anaesthetic technique compared with general anaesthesia in patients with CRF subjected to brachioaxillary graft for haemodialysis. The combined block provided an excellent anaesthetic coverage for the brachioaxillary graft area in the upper arm which compares with Guttman et al who performed both blocks in a 67-years old patient with metastasizing hepatocellular carcinoma planned for open reduction and internal fixation surgery of upper limb. They concluded that the combined block provides good anaesthesia for the entire right upper limb, and explained that SCB is a reliable technique giving anaesthesia for the distal arm and ISB increased the remaining quality of the motor and sensory blockade. ${ }^{16}$ In our study, we observed significant decrease in NRS in RA group during the 24 hour postoperative period that compares with Gebhard et al who reported the advantage of postoperative analgesia after regional anaesthesia. ${ }^{17}$

The significant reduction in frequency of analgesia requirement and the longer duration of the first need of analgesia in RA group could be explained by excellent analgesia of both blocks. This finding was confirmed by Bradley et al who stated that regional anaesthesia for patients with CRF requiring vascular access surgery reduces the need of postoperative analgesia and hastens their discharge. ${ }^{15}$ 
Interestingly, our study reported no phrenic nerve paralysis due to usage of a small volume ultrasound technique. ${ }^{18}$ This compares with Riazi et al who compared two volumes of local anaesthetics $(20$ versus $5 \mathrm{ml})$ in ISB and concluded that ultrasound guided mixture injection was associated with lower respiratory complications than the large volumes. ${ }^{19}$ Also Abdelhaq et al compared different doses in ISB (20, 15 and $10 \mathrm{ml}$ of mixture local anaesthetics bupivacaine $0.5 \%+$ lidocaine $2 \%$ ) combined with SCB (20ml of the same mixture) and found the combined block with reduced volume is an alternative to general anaesthesia without patient exposure to the risk of local anaesthetic toxicity. Moreover, the durations of sensory block and postoperative analgesia were lower with reduced volume. ${ }^{20}$

To our knowledge, only few studies have discussed combined SCB and ISBusage. ${ }^{1,16,20}$ Our study is the first to describe this combined block in patients with CRF.

\section{Conclusion}

Combined SCB and ISB technique using ultrasound guidance is an excellent alternative to general anaesthesia in patients with CRF subjected to brachioaxillary graft for haemodialysis. We reported better surgeon and patient satisfaction, lower NRS and frequency of analgesia requirement with delayed first need of analgesia.

\section{Conflict of interest: None}

Financial support: None

\section{References}

1. Ahmad H, Yadagiri M, Macrosson D, Majeed A. Above Elbow Amputation Under Brachial Plexus Block at Supraclavicular and Interscalene Levels. Anesthesiology and pain medicine. 2015;5(6):e24025.

https://doi.org/10.5812/aapm.24025

PMid:26705518 PMCid:PMC4688821

2. Fredrickson MJ, Krishnan S, Chen CY. Postoperative analgesia for shoulder surgery: a critical appraisal and review of current techniques. Anaesthesia.2010;65(6):608-624. https://doi.org/10.1111/j.1365-2044.2009.06231.x PMid:20565394

3. Liu SS, Zayas VM, Gordon MA, Beathe JC,
Maalouf DB, Paroli L, et al. A prospective, randomized, controlled trial comparing ultrasound versus nerve stimulator guidance for interscalene block for ambulatory shoulder surgery for postoperative neurological symptoms. Anesthesia \&Analgesia.2009;109(1):265-271. https://doi.org/10.1213/ane.0b013e3181a3272c PMid:19535720

4. Reiss W, Kurapati S, Shariat A, Hadzic A. Nerve injury complicating ultrasound/electro stimulationguided supraclavicular brachial plexus block. 2010; 35(4):400-401.

https://doi.org/10.1097/AAP.0b013e3181e90ec9 PMid:20607905

5. Renes SH, Spoormans HH, Gielen MJ, Rettig HC, van Geffen GJ. Hemidiaphragmatic paresis can be avoided in ultrasound-guided supraclavicular brachial plexus block. 2009; 34(6):595-599. https://doi.org/10.1097/AAP.0b013e3181bfbd83 PMid:19916254

6. Aitken E, Thomson P, Bainbridge L, Kasthuri R, Mohr B, Kingsmore D. A randomized controlled trial and cost-effectiveness analysis of early cannulation arteriovenous grafts versus tunneled central venous catheters in patients requiring urgent vascular access for hemodialysis. Journal of vascular surgery. 2017;65(3):766-774. https://doi.org/10.1016/j.jvs.2016.10.103 PMid:28236919

7. Shaikh SI, Veena K. Midazolam as an adjuvant in supraclavicular brachial plexus block. Anaesthesia, Pain \& Intensive Care. 2012;16(1):7-12.

8. Soares LG, Brull R, Lai J, Chan VW. Eight ball, corner pocket: the optimal needle position for ultrasound-guided supraclavicular block. Regional Anesthesia and Pain Medicine. 2007;32(1):94-95. https://doi.org/10.1097/00115550-200701000-

$\underline{00019}$

PMid:17196502

9. Neal JM, Gerancher JC, Hebl JR, Ilfeld BM, McCartney CJL, Franco CD, et al. Upper extremity regional anesthesia: essentials of our current understanding. Reg Anesth Pain Med. 2009;34(2):134-170. https://doi.org/10.1097/AAP.0b013e31819624eb PMid:19282714 PMCid:PMC2779737

10. Jadon A, Dixit S, Kedia SK, Chakraborty S, Agrawal A, Sinha N. Interscalene brachial plexus block for shoulder arthroscopic surgery: Prospective randomised controlled study of effects of $0.5 \%$ ropivacaine and $0.5 \%$ ropivacaine with 
Ghaffar et al. Sri Lankan Journal of Anaesthesiology: 28(2):74-79(2020)

dexamethasone. Indian journal of anaesthesia. 2015;59(3):171-176.

https://doi.org/10.4103/0019-5049.153039

PMid:25838589 PMCid:PMC4378078

11. Pongraweewan $\mathrm{O}$, Inchua $\mathrm{N}$, Kitsiripant $\mathrm{C}$, Kongmuang B, Tiwirach W. Onset time of $2 \%$ lidocaine and $0.5 \%$ bupivacaine mixture versus $0.5 \%$ bupivacaine alone using ultrasound and double nerve stimulation for infraclavicular brachial plexus anesthesia in ESRD patients undergoing arteriovenous fistula creation. $\mathrm{J}$ Med Assoc Thai. 2016;99(5):589-595.

12. Singelyn FJ, Lhotel L, Fabre B. Pain relief after arthroscopic shoulder surgery: a comparison of intraarticular analgesia, suprascapular nerve block, and interscalene brachial plexus block. Anesthesia \& Analgesia. 2004;99 (2) :589-592.

https://doi.org/10.1213/01.ANE.0000125112.83117. $\underline{49}$

PMid:15271745

13. Russel SMGS, Ahmad J, Ahmed R, Uddin J, Hosain SN. Brachio-Axillary Translocation Fistula with Reverse Saphenous Venous Graft: a New Hope for the Patients of End stage Renal Disease. Bangladesh Heart Journal. 2018;33(2):134-137. https://doi.org/10.3329/bhj.v33i2.39310

14. Salifu MO, Otah K. Perioperative management of the patient with chronic renal failure. Medscape; 2011.

15. Bradley T, Teare T, Milner Q. Anaesthetic management of patients requiring vascular access surgery for renal dialysis. Bja Education. 2017;17( 8):269-274.

https://doi.org/ Guttman OT, Soffer RJ, Rosenblatt MA. The Ultrasound-Guided SupraclavicularInterscalene (UGSCIS) Block: A Case Report. Pain Practice. 2008;8 (1) : 62-4.

https://doi.org/10.1111/j.1533-2500.2007.00156.x

PMid:17986160 10.1093/bjaed/mkx008

16. Russel SMGS, Ahmad J, Ahmed R, Uddin J, Hosain SN. Brachio-Axillary Translocation Fistula with Reverse Saphenous Venous Graft: a New Hope for the Patients of End stage Renal Disease. Bangladesh Heart Journal. 2018;33(2):134-137. https://doi. org/10.3329/bhj.v33i2.39310

17. Gebhard RE, Visan A, Maga G, Frohock J MA. Peripheral nerve blocks for surgical anesthesia in Haiti earthquale victims. Regional Anesthesia and Pain Medicine. 2010;35(5):1098-7339.
18. De Tran QH, Clemente A, Doan J, Finlayson RJ. Brachial plexus blocks: a review of approaches and techniques. Canadian Journal of Anesthesia/Journal canadiend'anesthésie. 2007;54(8):662-674.

https://doi.org/10.1007/BF03022962

PMid:17666721

19. Riazi S, Carmichael N, Awad I, Holtby RM, McCartney CJL. Effect of local anaesthetic volume $(20 \mathrm{vs} 5 \mathrm{ml})$ on the efficacy and respiratory consequences of ultrasound-guided interscalene brachial plexus block. British journal of anaesthesia. 2008;101(4):549-556.

https://doi.org/10.1093/bja/aen229

PMid:18682410

20. Abdelhaq MM, Kamal AM, Elramely MA. Different Volumes of Local Anesthetics in Ultrasound-Guided Combined InterscaleneSupraclavicular Block for Traumatic Humeral Fracture. Open Journal of Anesthesiology. 2016;6(4):55-62.

https://doi.org/10.4236/ojanes.2016.64009 